\title{
Erratum to: Update of complications and functional outcome of the ileo-pouch anal anastomosis: overview of evidence and meta-analysis of 96 observational studies
}

Sharonne de Zeeuw • Usama Ahmed Ali •

Rogier A. R. T. Donders • Willem E. Hueting •

Frederik Keus • Cees J. H. M. van Laarhoven

Published online: 15 February 2012

(C) Springer-Verlag 2012

Erratum to: Int J Colorectal Dis

DOI 10.1007/s00384-011-1402-6

The online version of this article unfortunately contained a mistake. The correct abbreviation of the author's name Usama Ahmed Ali in the footnote is U. Ahmed Ali.

The online version of the original article can be found at http://dx.doi. org/10.1007/s00384-011-1402-6.

S. de Zeeuw $(\bowtie) \cdot$ U. Ahmed Ali $\cdot$ F. Keus •

C. J. H. M. van Laarhoven

Department of Surgery, (Division of Abdominal Surgery),

Radboud University Nijmegen Medical Centre,

PO Box 9101, 6500 HB Nijmegen, The Netherlands

e-mail: s.dezeeuw@chir.umcn.nl

R. A. R. T. Donders

Department of Epidemiology, Biostatistics and HTA,

Radboud University Nijmegen Medical Centre,

Nijmegen, The Netherlands

W. E. Hueting

Department of Surgery, Diakonessenhuis,

Leiden, The Netherlands 